\title{
Removal of Ammonia from Wastewater by Natural Freezing Method
}

\author{
Xingjian Jiang \\ China Shenhua Coal To Liquid and Chemical CO., \\ LTD. \\ The Quality Department \\ Baotou, China \\ e-mail: jiangxingjian@csclc.com
}

\author{
Zihong Cheng, Wei Ma*, Zhanxian Gao, Xuehu \\ Ma, Ren Wang \\ Department of Chemistry \\ Dalian University of Technology \\ Dalian, China \\ e-mail: naranjas@mail.dlut.edu.cn
}

\begin{abstract}
A novel process, natural freezing, was developed to remove ammonia from wastewater in this study. A series of experiments were carried out to examine the ammonia removal and ice productivity in laboratory in Dalian, the effect of operating conditions such as solution concentration, pH, ice content formed, and $\mathrm{Na}^{+}$concentration were conducted. The results showed that the natural freezing method could effectively remove ammonia from wastewater; about $80 \%$ ammonia was removed at about $500 \mathrm{mg} / \mathrm{L}$ initial ammonia concentration, while the fraction of ice formed was about $50 \%$ controlling the $\mathrm{pH}$ at 7 . When the freezing process was carried out under natural temperature conditions, the obvious advantage was the savings in energy. Unlike mechanical freezing process, natural freezing usually did not require complex facilities and thus is simple and less expensive to operate. Therefore, the natural freezing method was characterized by low pollution, simple facility, low energy consumption, and it is feasible in most of regions north of China because of the long winter and low temperature conditions. This study could introduce the fundamental principle and research development of the natural freezing method.
\end{abstract}

Keywords- freezing; ice crystal; wastewater; Ammonia

\section{INTRODUCTION}

With the rapid expansion of industrial developments and intensification of human activities, the environmental was suffered from the emissions of industrial wastewater containing ammonia nitrogen [1]. Coking wastewater, generated from coke plants and coal gasification plants, contained high amount of ammonia, phenol, cyanide, thiocyanate, and other aromatic hydrocarbons, as well as a variety of nitrogen, oxygen or sulfur-containing heterocyclic compounds [2]. The wastewater containing ammonia nitrogen may cause eutrophication and produce toxic substances if discharged into the aquatic eco-system. Ammonia also increases chlorine consumption for water disinfection and industrial circulating water sterilization treatment. It is therefore imperative to remove ammonia nitrogen during the wastewater treatment, which could add to the difficulty and cost of the treatment. Thus, it should be paid more attention to the removal nitrogen especially ammonia-nitrogen from waste water. Therefore, some methods for removal of ammonia, such as ammonia stripping [3], adsorption [4], chemical precipitation [5], biological nitrification [6], electrochemical conversion [7], and microbial fuel cell [8] have been reported. Biological nitrification is the most common process in the treatments of ammonia nitrogen wastewater. But the process is only suitable for the removal of relatively low ammonia concentration at suitable temperature. Ammonia stripping makes use of stripping tower and consumes much energy. Chemical precipitation needs additional reagents, which may introduce new pollutants, while electrochemical method often uses expensive metal as electrodes and also consumes large quantity of energy.

Freezing has been recognized as an effective technology to remove the contaminants from water. It was based on the fact that the ice crystals are essentially made up of pure water. During the process of freezing process, the salt (or contaminants) are excluded during the formation of ice crystals leading to a separation of ice and concentrated salt [9]. There are series of freezing types have been reviewed previously, which is classified by the freezing process used, included: direct contact freezing, vacuum freezing, indirect contact freezing and eutectic separation [10]. Natural freezing method was based on the freeze concentration to treat the wastewater. It could be applied to most of wastewater by separating a large amount of water in the form of ice achieving concentrated wastewater. This method derived from 17th century and was used to keep foods fresh, concentrate some substance or used in medicine domains. Freezing water needed about $335 \mathrm{~kJ} / \mathrm{kg}$ heat, while evaporating water at $100{ }^{\circ} \mathrm{C}$ and $0^{\circ} \mathrm{C}$ needed about $2248 \mathrm{~kJ} / \mathrm{kg}$ and $2495 \mathrm{~kJ} / \mathrm{kg}$, respectively [11]. It was indicated that freezing method was more efficient with respect to energy saving and that the freethaw process would be an optimal option in places with cheap freezing energy (a cold climate). Theoretically, the freezing method was an operation which would save a lot of energy source and make lower pollution. And most places north of China, where are long winter with low temperature, offer suitable operational conditions for this method. M. Maurer et al. reported that between seven main purposes of urine treatment processes including $\mathrm{N}$ recovery process. Ammonia was the mainly composition of nitrogen in urine and at least $90 \%$ ammonia recovery was achieved with evaporation, electrodialysis, reverse osmosis and struvite precipitation, while between $80 \%$ and $90 \%$ was achieved with freeze-thaw process and most likely with ammonia stripping [12]. However, few references were found in the literature pertaining to the 
ammonia removal from wastewater containing high ammonia concentration using the natural freezing method.

There are two essential methods for ice crystallization. One is layer crystallization on the cool surface and the other is suspension crystallization of granular ice in cooled solution, which is also named Bulk crystallization. The ice layer grew uniformly from the top to the bottom in the ice making container. The ice layer formed was hard with smaller solid-liquid interface and easy separation of ice from concentrated wastewater was achieved [13]. Suspension crystallization was characterized by a lot of ice grain suspending in the mother liquor freely, and then ice grain grew up in the container gradually. This process increased the concentration of the mother liquor, and separated the ice and the concentrated solution. The layer crystallization seemed more advantageous than suspension crystallization because the device structure was much simpler. It was also beneficial from the view of separation, because a smaller surface area per unit mass of ice could be obtained.

Freezing wastewater treatment involves some other advantages: It could be applied to treat the sewage containing toxic compounds or heavy metals, which are difficult to be treated by the biological wastewater treatment. The ice crystal produced can be used in other fields. Besides, the facility required is simpler than that for other wastewater treatment technologies.

Therefore, the objectives of this study are: (I) to investigate the removal of ammonia from coal chemical industry wastewater by freezing concentration during the natural freezing process in winter of north China; (II) to determine the effects of operating conditions such as initial ammonia concentration of wastewater, $\mathrm{pH}$, fraction of ice formed, and cation ion $\mathrm{Na}^{+}$on the ammonia separation efficiency from wastewater contained high ammonia concentration at the temperature between $0{ }^{\circ} \mathrm{C} \sim-12{ }^{\circ} \mathrm{C}$.

\section{MATERIALS AND METHODS}

\section{A. Materials and reagents}

Ammonia chloride, purchased from Kermel, Tianjin, was used to prepare ammonia solution in this experiment. Nessler reagent was confected from sodium hydroxide, potassium iodide, and mercurous iodide which were purchased from Kermel, Tianjin. Potassium sodium tartrate was used to determine ammonia in solution before and after natural freezing. In freezing experiments, diluted hydrochloric acid and sodium hydroxide were used to adjust the solution $\mathrm{pH}$, and sodium chloride was applied to investigate the influence of co-existing ion on ammonia removal. All chemicals used in this study were analytical reagent grade and used without further purification.

Instruments: The $\mathrm{pH}$ of the solution was measured by pH meter (PHS-2 Model, Hangzhou, China). The ammonia concentration was analyzed by spectrophotometer (Model 721, Shanghai, China).

\section{B. Experiment fundamental}

The phase diagram was showed in Fig.1.

Natural freezing method was based on the solid-liquid equilibrium relationship of the solution which was characterized by freezing point depression, eliminating the water as ice form from the solution.

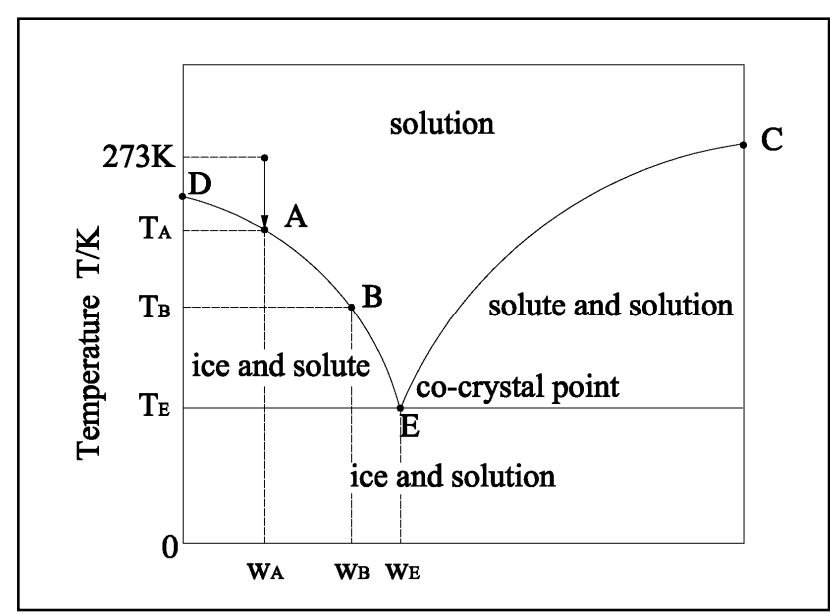

Figure 1. Phase equilibrium of the freezing solution.

As shown in Fig. 1, the composition of the substance was represented by mass fraction. The part on the left of point $E$ was related to the freezing method, and the $D E$ curve illustrated the relationship between the solution composition and the freezing point. Above the curve, it represented liquid state, while coexisted as ice and solution was below. At the temperature $T$, the mass fraction of the solution was $w_{\mathrm{A}}$. The solution was freeze to temperature $T_{\mathrm{A}}$ and ice crystals appeared, $T_{\mathrm{A}}$ was defined as the freezing point. The solution was continuous freeze to point $B$, the concentrated solution composition increased to $w_{\mathrm{B}}$, and the freezing temperature decreased to $T_{\mathrm{B}}$, Theoretically, the solution could be concentrated to mass fraction $w_{\mathrm{E}}$ finally.

\section{The conditions and methods of the experiment}

The ammonia contained solutions were placed outdoors, in Dalian University of Technology, Dalian, China during winter. The operation was performed under the ambient temperature conditions at $-6{ }^{\circ} \mathrm{C} \sim-12{ }^{\circ} \mathrm{C}$ for $10-12 \mathrm{~h}$ to form ice crystal. Then, the ice and the concentrated solution were separated, the concentrations of ammonia in the pure water thawed from ice were determined. The initial ammonia concentrations of 100 , 200, 500, 1000, $5000 \mathrm{mg} / \mathrm{L}$ were used to investigate the influence of initial concentration. 50, 100, 250, 500, and $1000 \mathrm{~mL}$ of ammonia contained wastewater with the ammonia concentration of $500 \mathrm{mg} / \mathrm{L}$ were applied to study the influence of content of ice formed on ammonia removal. The $\mathrm{pH}$ of the solution with $500 \mathrm{mg} / \mathrm{L}$ ammonia concentration were adjusted to 3, 5, 7, 9 and 11 by using diluted hydrochloric acid and sodium hydroxide was conducted to investigate the influence of solution $\mathrm{pH}$. Sodium chloride was applied to study the content of sodium ion on ammonia remvoal.

Use formula (1) to calculate the desalting efficiency:

$R=\left(C_{0}-C_{\mathrm{t}}\right) \times 100 \% / C_{0}$

The fraction of ice formed was worked out from the formula as follow:

$P=V_{\mathrm{t}} \times 100 \% / V_{0}$

where $R$ is ammonia removal efficiency (\%), $C_{0}$ and $C_{\mathrm{t}}$ are the initial and final ammonia concentration in the wastewater $(\mathrm{mg} / \mathrm{L}), P$ is the fraction that ice formed (\%), $V_{0}$ and $V_{\mathrm{t}}$ are the volume of the wastewater before and after freezing process $(\mathrm{mL})$. 


\section{RESULTS AND DISCUSSION}

\section{A. Effect of initial ammonia concentration on ammonia removal}

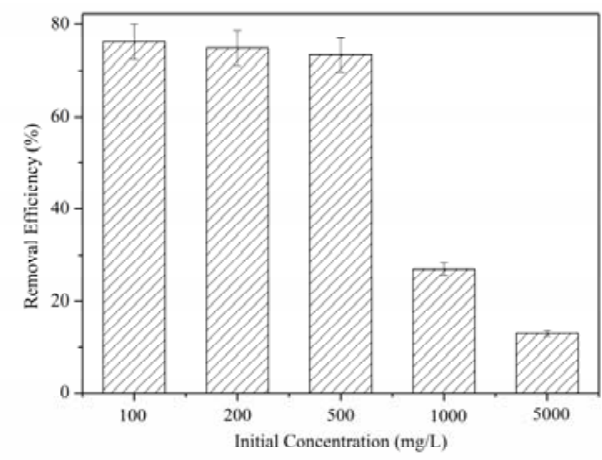

Figure 2. Effect of initial concentration on ammonia removal.

Fig.2 illustrated that ammonia removal efficiency was about $70-80 \%$ at initial ammonia concentration below 500 $\mathrm{mg} / \mathrm{L}$, while the ammonia removal efficiency decreased obviously when the ammonia concentration increased to more than $1000 \mathrm{mg} / \mathrm{L}$. It could be noted that the natural freezing method had excellent ammonia removal efficiency from wastewater. It attributed to the growth of ice crystals excluding the contaminations from the ice, but there were dendritic of spike-shape ice crystals with gaps appearing during the growth of ice crystals. Lots of contaminations entrapped in the gaps resulting in lower removal efficiency.

\section{B. Effect of ice content on ammonia removal}

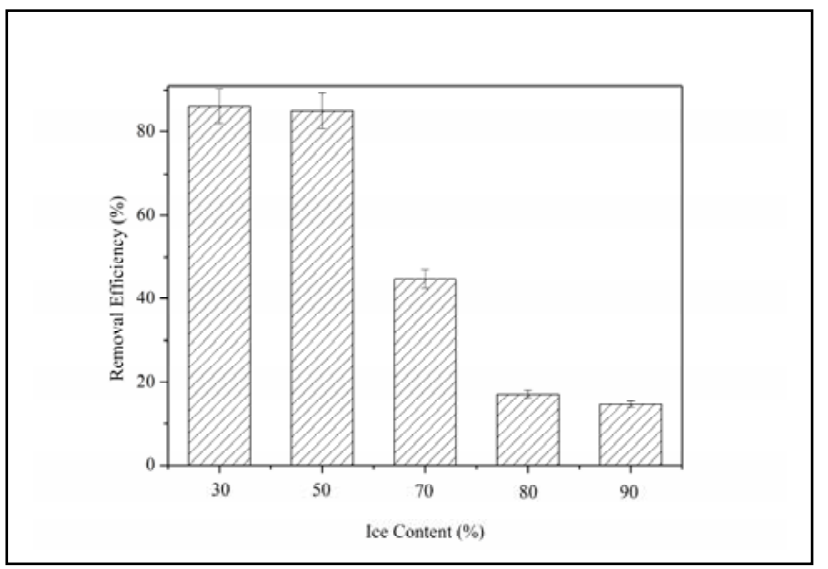

Figure 3. Effect of the ice content on ammonia removal.

Fig. 3 showed the relationship between ammonia removal efficiency and the ice ratio. The column indicated that the removal efficiency increased with the decrease of icing ratio. A higher purity of ice layer was found when the icing ratio below $50 \%$ and simultaneously the removal efficiency would be about $80 \%$ steadily. As the fraction of ice formed greater than $95 \%$, all of the water in the containers turned into ice phase, therefore, all contaminants were entrapped into the ice structure again, no ammonia separation occurred during the process. But it was somewhat surprising that the removal efficiency decreased in some sort with low icing ratio $(<30 \%)$. The reason for the phenomenon was that although the volume of ice was small, the relatively large exposed surface area per unit volume and the more gaps appeared between the ice crystals made more impurities trapped in and subsequently decreased the ammonia removal efficiency.

Therefore, the objective was to control the freezing conditions to generate an appropriate volume (the content of ice formed was approximately $50 \%$ ) of the ice phase with the higher impurity removal efficiency possible.

\section{Effect of $\mathrm{pH}$ on ammonia removal}

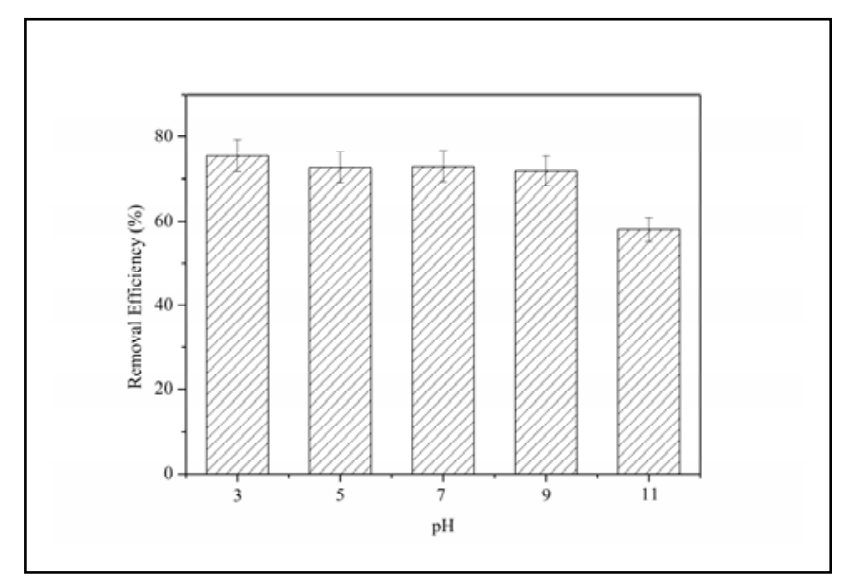

Figure 4. Effect of solution $\mathrm{pH}$ on ammonia removal.

It illustrated the removal of ammonia at different $\mathrm{pH}$. There was more than $70 \%$ ammonia removed when $\mathrm{pH}$ at $3,5,7$ and 9 , while the ratio decreased to about 50 percent when $\mathrm{pH}$ at 11 . In aqueous solution, ammonia existed as two forms in following equilibrium (a) as a function of $\mathrm{pH}$, ionic strength and temperature.

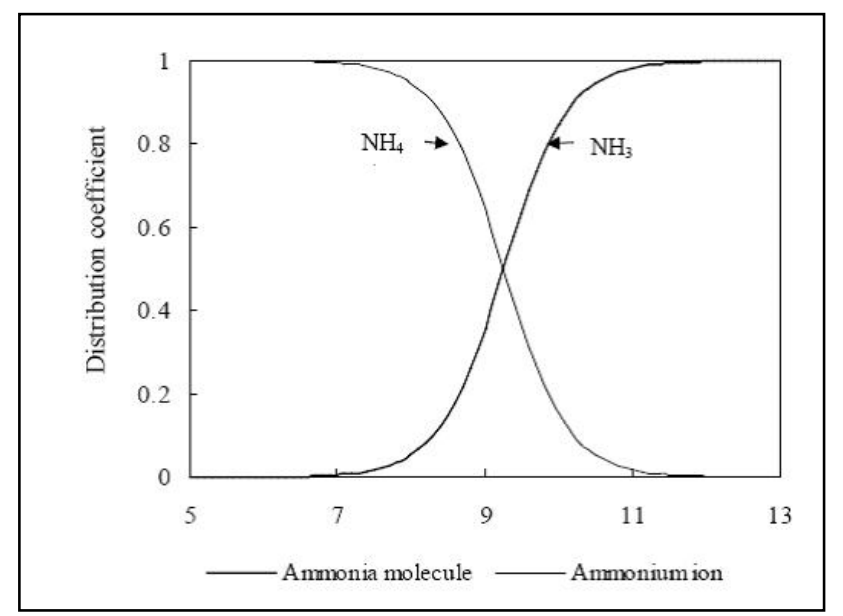

Figure 5. Distribution coefficients of $\mathrm{NH}_{3}$ and $\mathrm{NH}_{4}{ }^{+}$at different $\mathrm{pH}$ $\left(20^{\circ} \mathrm{C}\right)$.

Ionic strength and temperature influenced ammonia speciation, $\mathrm{pH}$ is the controlling variable. Consequently, with a $p K_{\mathrm{b}}$ of 9.5, at $\mathrm{pH}$ less than 9.5, most ammonia present in solution is $\mathrm{NH}_{4}^{+}$, while at $\mathrm{pH}$ greater than 9.5 the majority is $\mathrm{NH}_{3} \cdot \mathrm{H}_{2} \mathrm{O}$ [14]. In reaction (b), was the distribution of $\mathrm{NH}_{3} \cdot \mathrm{H}_{2} \mathrm{O}$. It was the fraction of $\mathrm{NH}_{3} \cdot \mathrm{H}_{2} \mathrm{O}$ 
in total ammonia, while $\left[\mathrm{NH}_{4}{ }^{+}\right]$was the concentration of $\mathrm{NH}_{4}^{+}$and $\left[\mathrm{NH}_{3}\right]$ was the concentration of $\mathrm{NH}_{3} \cdot \mathrm{H}_{2} \mathrm{O}$ in solution. Fig. 5 showed the distribution coefficients of $\mathrm{NH}_{4}{ }^{+}$and $\mathrm{NH}_{3}$ at different $\mathrm{pH}$. It has been established that temperature had minute influence on the distribution coefficients [15]. From this Fig. we can see, in acidic and neutral media of low $\mathrm{pH}$, ammonia nitrogen was presented as $\mathrm{NH}_{4}^{+}$, while the ionic $\mathrm{NH}_{4}^{+}$converted to non-ionic $\mathrm{NH}_{3} \cdot \mathrm{H}_{2} \mathrm{O}$ at high $\mathrm{pH}$ above 9.5 , this also accorded to the $p_{\mathrm{Kb}}$ discussed above.

In this natural freezing process, the high $\mathrm{pH}$ above 9 accelerated the equilibrium between $\mathrm{NH}_{4}{ }^{+}$and $\mathrm{NH}_{3}$ to molecular $\mathrm{NH}_{3}$ dissolved in the solution. Fig.4 indicated that the ammonia removal efficiency was decreased with the increase of $\mathrm{pH}$. It implied that the more molecular $\mathrm{NH}_{3}$ resulted from the higher $\mathrm{pH}$ appeared in the water system, the lower ammonia removal efficiency obtained.

$$
\begin{aligned}
& \mathrm{NH}_{4}{ }^{+}+\mathrm{OH}^{-}=\mathrm{NH}_{3}+\mathrm{H}_{2} \mathrm{O} \\
& \alpha_{\mathrm{NH}_{3}}=\left[\mathrm{NH}_{3}\right] /\left(\left[\mathrm{NH}_{3}\right]+\left[\mathrm{NH}_{4}{ }^{+}\right]\right)
\end{aligned}
$$

D. Effect of the existent of positive ions (consider sodium ion primarily) on the ammonia removal

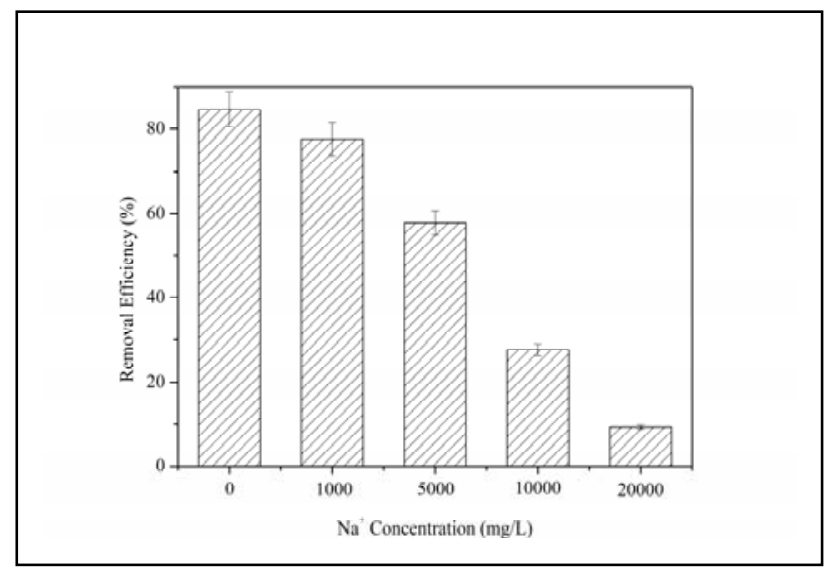

Figure 6. Effect of $\mathrm{Na}^{+}$concentration on ammonia removal.

Fig. 6 showed the effect of the concentration of $\mathrm{Na}^{+}$ contained in the solution on ammonia removal efficiency with an initial ammonia concentration of $500 \mathrm{mg} / \mathrm{L}$. Each column represented an average value of ammonia removal efficiency of five samples of melted ice. The results obtained from the experiment indicated that the existence of $\mathrm{Na}^{+}$had remarkable influence to the removal efficiency of ammonia in a certain extent. The increase of $\mathrm{Na}^{+}$ concentration resulted in reducing removal efficiency in the ice corresponding to each sample.

\section{CONCLUSIONS}

Experimental results obtained from above study demonstrated that natural freezing was a simple and effective method to remove ammonia from wastewater. Partial freezing by controlling the content of ice formed at $50 \%$ could effectively reduce ammonia concentration in solution. About $80 \%$ ammonia removal efficiency was achieved when the ice content formed was $50 \%$ with the initial ammonia concentration was $500 \mathrm{mg} / \mathrm{L}$ and the $\mathrm{pH}$ of the solution was 7 , under the operation conditions that the lowest temperature ranged from $-9{ }^{\circ} \mathrm{C} \sim-12{ }^{\circ} \mathrm{C}$. It could be concluded that natural freezing method could effectively remove ammonia from wastewater with advantages of low pollution, simple facility, low energy consumption, and it was feasible in most of regions north of China where with a long winter and low temperature conditions.

\section{ACKNOWLEDGMENT}

Financial supports from the National High Technology Research and Development Program (“863” program) of China (2012AA06A115), and China Postdoctoral Science Foundation (2014M551090) were gratefully acknowledged.

\section{REFERENCES}

[1] J. A. Camargo, A. Alonso, "Ecological and toxicological effects of inorganic nitrogen pollution in aquatic ecosystems: a global assessment,” Environ. Int. vol. 32, pp. 831-849, August 2006.

[2] X. Du, R. Zhang, Z. X. Gan, J. H. Bi, “Treatment of high strength coking wastewater by supercritical water oxidation,” Fuel, vol. 104, pp. 77-82, February 2013.

[3] L. Zhang, Y. W. Lee, D. Hahng, “Ammonia stripping for enhanced biomethanization of piggery wastewater,” J. Hazard. Mater. Vol. 199-200, pp. 36-42, January 2012.

[4] G. Markou, D. Vandamme, K.Muylaert, "Using natural zeolite for ammonia sorption from wastewater and as nitrogen release for the cultivation of Arthrospira platensis,” Bioresour. Technol. Vol. 155, pp. 373-378, March 2014.

[5] X. Z. Li, Q. L. Zhao, X. D. Hao, "Ammonium removal from landfill leachate by chemical precipitation,” Waste Manage, vol. 19, pp. 409-415, October 1999.

[6] B. L. Hou, H. J. Han, S. Y. Jia, H. F. Zhuang, Q. Zhao, P. Xu, "Effect of alkalinity on nitrite accumulation in treatment of coal chemical industry wastewater using moving bed biofilm reactor," J. Environ. Sci. vol. 26, pp. 1014-1022, May 2014.

[7] W. T. Mook, M. H. Chakrabarti, M. K. Aroua, G. M. A. Khan, B. S. Ali, M. S. Islam, M. A. Abu Hassan, "Removal of togal ammonia nitrogen (TAN), nitrate and total organic carbon (TOC) from aquaculture wastewater using electrochemical technology: A review,” Desalination, vol. 285, pp. 1-13, January 2012.

[8] X. Y. Zhang, F. Zhu, L. Chen, Q. Zhao, G. H. Tao, "Removal of ammonia nitrogen from wastewater using an aerobic cathode microbial fuel cell,” Bioresour. Technol. Vol. 146 pp. 161-168, October 2013.

[9] P. M. Williams, M. Ahmad, B. S. Connolly, D. L. Oatley-Radcliffe, "Technology for freeze concentration in the desalination industry," Desalination, vol. 356, pp. 314-327, January 2015.

[10] M. V. Rane, Y. S. Padiya, "Heat pump operated freeze concentration system with tubular heat exchanger for seawater desalination,” Energy Sustain. Dev. Vol. 15, pp. 184-191, 2011.

[11] L. Liu, Y. Xue, J. Zhang, "Brief introduction of application and research in freeze concentration technology,” Chem. Ind. Eng. Vol. 16 pp. 151-1560, 1999.

[12] M. Maurer, W. Pronk, T. A. Larsen, "Treatment processes for source-separated urine,” Water Res. Vol. 40, pp. 3151-3166, 2006.

[13] M. Wakisaka, Y. Shirai, S. Sakashita, "Ice crystallization in a pilotscale freeze wastewater treatment system,” Chem. Eng. Process. Vol. 40 pp. 201-208, May 2001.

[14] R. M. Burgess, M. C. Pelletier, K. T. Ho, "Removal of ammonia toxicity in marine sediment TIEs : a comparison of Ulva lactuca, zeolite and aeration methods," Marine Pollution Bulletin vol. 46 pp. 607-617, May 2003.

[15] L. Lin, S. H. Yuan, J. Chen, Z. Q. Xu, X. H. Lu, "Removal of ammonia nitrogen in wastewater by microwave radiation," J. Hazard. Mater. Vol. 161, pp. 1063-1068, January 2009 